authorities and researchers of occupational accidents are interested in learning about the investigation methods of road accidents, and vice versa. The aim of this study was to analyse past road accidents as occupational accidents, in the hope of gaining a better understanding of the work-related risks involved.

Methods The data collected from the Finnish Motor Insurer's Centre's databases. One quantitative analysis was performed using data from fatal heavy traffic accidents from 1991 to 2011. Two qualitative analyses were performed: the first used data from fatal accidents from 2010 to 2012, while the second covered accidents which led to the death of the driver of a heavy vehicle from 2011 to 2013.

Results Both qualitative analyses indicated that there were a number of work-related risks contributing to the accidents, for example poor planning, excessive work hours and tight timetables. The quantitative analysis contained some indications of driver-related risks that, in the qualitative analyses, might also be seen as work-related risks. For example, one reason for an accident was the driver's fatigue, while the underlying reason might have been poor logistical planning.

Conclusions The qualitative results give more information about work-related risks and verify a new point of view for improving the safety of professional driving in heavy traffic. The workrelated risks indicate that safety information is important to include in educational material, not only for drivers, but also for all planners and other people in the logistics chain.

\section{IMPROVING SAFETY AWARENESS IN WASTE TRANSPORT WORK}

Pia Perttula, Simo Salminenand Vuokko Puro. Finnish Institute of Occupational Health Finland

\subsection{6/injuryprev-2016-042156.149}

Background Improving resilience in waste transport is essential for the successful management of operations despite the changes and disruptions that take place during the working day. Waste transfers are an example of work in which unpredictable events occasionally occur, and workers need to make quick decisions on how to operate in order to perform all their work in the given time. Being prepared for disruptions and changes helps workers react and continue working without causing extra delays, and this preparedness increases their safety, health and well-being.

Methods The outcome of the study is a tool for workplaces. This tool was developed after gathering and analysing data from participating companies by present state analysis. Participants also answered a questionnaire on undesired events and waste transport workers' reactions to sudden changes and outcomes.

Results The significance of management for safety in a waste transport worker's everyday work seems substantial. The tool created for improving the safety of waste transport workers requires managers of waste transport companies to present safety issues monthly. These monthly brief information packages include questions to activate waste transport workers to think about, for example, how to handle excessively heavy waste cans, or guidance on working in high temperatures.

Conclusions The importance of safety is appreciated by both foremen and workers. However, the need to perform one's job in a given time may often surpass safety requirements. This is why safety issues need to be regularly addressed and practically communicated to workers. This tool for directly addressing safety issues on a monthly basis among a particular occupational group was created in order to improve workers' safety.

\section{USING LOCAL CONTEXT TO INFORM ROAD TRAFFIC INJURY PREVENTION IN GLOBAL EMPLOYEE WELLNESS PROGRAMS}

${ }^{1}$ Sara F Jacoby, ${ }^{2}$ Flaura K Winston, ${ }^{3}$ Therese S Richmond. ${ }^{1}$ Penn Injury Science Center, University of Pennsylvania, USA; ${ }^{2}$ The Perelman School of Medicine at the University of Pennsylvania and the Children Hospital of Pennsylvania, USA; ${ }^{3}$ University of Pennsylvania School of Nursing, USA

\subsection{6/injuryprev-2016-042156.150}

Background Multinational corporations (MNCs) can contribute to their employees' wellness through global interventions aimed at road traffic injury prevention, particularly in high risk settings. The purpose of this study was to understand the road use experiences of employees of a large U.S. MNC in India to inform a globally enacted and locally relevant employee road safety platform.

Methods Surveys and focus group interviews were used to elicit road safety perceptions, attitudes and behaviours of employees in MNC offices in the cities of Bangalore and Pune. Survey responses were analysed to describe demographic, vehicular, and behavioural features of a representative sample of employees. Focus group transcripts were coded to develop a thematic framework that described the road traffic experiences of employees in their local environment and perceptions of interventions that would enhance their safety.

Results Seventy-five employees completed surveys and participated in one of six focus group interviews. Participants considered daily road use to be a dangerous and stressful experience. Roadway danger was attributed to vehicle mix, non-adherence to traffic laws, and transportation infrastructure unequipped for the rate of population and commercial growth. Focus groups identified inconsistencies between employee knowledge of safety strategies and their road use behaviours, and policy-level actions that could be instituted.

Conclusions This study uncovered that an employee road safety intervention for MNC employees in the context of urban India should focus on behaviour change and structural interventions that take into account roadway infrastructure, traffic patterns, and enforcement of traffic policies. It further demonstrates how simple strategies can be used to elicit important contextual road safety factors amoung MNC employees globally in order to identify locally relevant interventions for employee injury prevention.

\section{NATIONAL OCCUPATIONAL INJURIES IN THE PHILIPPINES: IMPLICATIONS FOR SAFETY PROGRAMS}

Jinky Lu. Institute of Health Policy and Development Studies, National Institutes of Health University of the Philippines Manila, Philippines

\subsection{6/injuryprev-2016-042156.151}

Background This study aimed to review and assess the prevalence and incidence of occupational injuries in the Philippines. The study collated and analysed available data from national and international sources. Hospital-based and population-based data on types of injury such as motor vehicle crashes, falls, burns, drowning, poisoning, and suicides were included in the study in order to get a comparative statistics for occupationally related injuries compared to overall injuries in the country. 
Methods Data collection was done from various agencies, namely, Bureau of Labour and Employment Statistics (BLES) of the Department of Labour and Employment (DOLE), Labour Force Survey of National Statistics Office, Occupational Safety and Health Centre (OSHC), National Electronic Injury Surveillance System (NEISS) under Department of Health (DOH), Overseas Employment Statistics (OES) of the Philippine Overseas Employment Administration (POEA), and International Labour Organisation (ILO).

Results Occupational injuries in the Philippines showed 22,265 cases in 2003, and 47,235 cases in 2007. The manufacturing industries registered the highest number of cases Out of the reported cases of occupational injuries, 178 resulted in death in 2000, and 116 deaths in 2007. Injury occurred at 6 injury cases per 500 full-time workers in 2000. In the following years, it declined to 4 cases per full-time worker in 2003, and 3 cases for every 88 workers in 2007. Superficial injuries and open wounds were the most common type of injuries. Acute poisoning and infections increased by 2.39 times from 2003 to 2007. Other serious injuries were burns, corrosions, scalds, and frostbites and still registering with 2,065 cases in 2007. Fractures also registered at 1,839 cases in 2007. Based on hospital records, there was a total of 9,521 injury cases reported for the first quarter of 2010 in 77 government and private hospitals in the country. The cause of injury mostly occurred on the road (44.4\%), and work-related injuries were reported at $7.8 \%$.

Conclusions The records and data show that occupational injuries are prevalent in the Philippines. It is suggested that data collection on occupational injuries be a national scale, and not merely randomised collection of data from small, medium and large industries. Data on occupational injury should also include the agricultural sector, the informal sector, and small enterprises.

\section{Sports and Exercise Safety}

\section{Parallel Mon 2.5}

\section{EXERCISE TRAINING TO PREVENT SPORTS INJURIES: RESULTS FROM A CLUSTERED RANDOMISED CONTROLLED TRIAL}

${ }^{1}$ Caroline F Finch, 'Lauren Fortington, ${ }^{1}$ Akram Muhammed, 'Dara Twomey, ${ }^{2}$ Tim Doyle, ${ }^{2}$ Bruce Elliott, ${ }^{2,3}$ David Lloyd. ${ }^{1}$ Federation University Australia, Australia; ${ }^{2}$ University of Western Australia, Australia; ${ }^{3}$ Griffith University, Australia

\subsection{6/injuryprev-2016-042156.152}

Background Exercise-based training programs are a popular injury prevention measure to prevent sports injuries but there have been few trials of their effectiveness in real-world sports settings.

Methods A clustered randomised controlled trial was undertaken in 18 community-level (non-elite) Australian Football (AF) clubs in two states with multiple teams of adult male players. Clubs/ teams were randomly allocated to either a neuromuscular control (NMC) (intervention $\mathrm{n}=679$ players) or standard-practice (control $\mathrm{n}=885$ players) exercise training program delivered as part of regular team training sessions (twice weekly over an 8-week pre-season and 18-week regular-season). All game-related injuries and hours of game participation were recorded. Training attendance was recorded as a proxy for compliance with the allocated program. Generalised estimating equations, adjusted for clustering (club), were used to compute injury incidence rates (IIR) for all injuries, lower limb injuries (LLI) and knee injuries only. Using an intention-to-treat analysis, the IIRs were compared across groups with cluster-adjusted injury rate ratios (IRR).

Results A total of 773 game injuries was recorded, of which 50\% ( $\mathrm{n}=386)$ were LLI and $12 \%(\mathrm{n}=96)$ were to the knee. Compared with control players, NMC players had both a reduced overall LLI rate (IRR: 0.78 (95\% CI: 0.56 to 1.08), $\mathrm{p}=0.14$ ) and knee IRR (IRR: 0.50 (95\% CI: 0.24 to 1.05 ), $\mathrm{p}=0.07$ ). Variation in player training attendance across the season influenced exposure to the implemented programs.

Conclusions Injury reductions can be achieved from implementing targeted training programs in men's community sport. While nearly statistically significant, reducing the knee injury rate by half and the LLI rate by $22 \%$ is still a clinically important outcome. Further injury reductions could be achieved with improved training attendance and participation in the program.

\section{CONCUSSIONS IN UNITED STATES HIGH SCHOOL BOYS' AND COLLEGE MEN'S ICE HOCKEY PLAYERS}

${ }^{1}$ Zachary Y Kerr, ${ }^{2}$ Lauren A Pierpoint, ${ }^{2}$ Dustin W Currie, ${ }^{3}$ John M Rosene, ${ }^{3}$ Paul S Visich, ${ }^{1}$ Thomas P Dompier, ${ }^{2} \mathrm{R}$ Dawn Comstock. 'Datalys Centrefor Sports Injury Research and Prevention, USA; ${ }^{2}$ Program in Injury Prevention, Education and Research (PIPER), Department of Epidemiology, Colorado School of Public Health, USA; ${ }^{3}$ Exercise and Sport Performance Department, University of New England, USA

\subsection{6/injuryprev-2016-042156.153}

Background Research in high school and college sports has found high concussion rates in ice hockey. This study describes the epidemiology of concussions in high school boys' and college men's ice hockey.

Methods Data originates from High School RIO during the 2008/09-2014/15 academic years (191 team-seasons); and the National Collegiate Athletic Association Injury Surveillance Program (NCAA-ISP) during the 2009/10-2014/15 academic years (148 team-seasons). A reportable concussion occurred as a result of participation in an organised game/practice and required attention from an athletic trainer or physician. Concussion injury rates per 10000 athlete-exposures (AE), injury rate ratios (RR), and 95\% confidence intervals (CI) were calculated.

Results Overall, 279 and 309 concussions were reported in high school boys' and college men's ice hockey, respectively, for rates of 6.8 and 7.6/10000 AE. Player contact was the most common injury mechanism in boys (46.6\%) and men (71.5\%). Contact with boards comprised a larger proportion of concussions in boys $(31.2 \%)$ than men (9.4\%). Checking was the activity during which injury occurred for $42.7 \%$ of boys' and $28.5 \%$ of men's concussions. Concussion rates did not differ between boys and men $(\mathrm{RR}=0.9 ; 95 \% \mathrm{CI}: 0.9-1.3)$. However, the concussion rate due to player contact was higher in men than boys $(\mathrm{RR}=1.7$, 95\% CI: 1.4-2.1). In contrast, concussion rates due to contact with boards (RR $=3.0,95 \%$ CI: 2.0-4.6) and checking $(\mathrm{RR}=1.3,95 \% \mathrm{CI}: 1.0-1.8)$ were higher in boys than men.

Conclusions Although overall concussion rates did not differ between high school boys' and college men's ice hockey players, mechanism- and activity-specific rates varied. Such differences may be associated with physical maturation differences between high school boys' and college men's ice hockey athletes, and may indicate a need for continued skill development at lower levels of competition. 